\title{
Melatonin secretion from organ-cultured pineal glands of rats: modulation by gonadectomy and gonadotropin-releasing hormone agonist administration
}

Bunpei Ishizuka, Shigeyoshi Fusama, Kunihko Hirai, Takeshi Hosaka, Naomi Hamada, Akira Amemiya and Masanori T Itoh ${ }^{1}$

Department of Obstetrics and Gynecology, and ${ }^{1}$ Department of Chemistry, St Marianna University School of Medicine, Sugao, Miyamae-ku, Kawasaki 216-8511 Japan

(Correspondence should be addressed to B Ishizuka; Email: ishizuka@marianna-u.ac.jp)

\begin{abstract}
The objective of the study was to evaluate the effect of pretreatments such as gonadectomy in male and female rats, and gonadotropin-releasing hormone agonist (GnRHa) administration in female rats, on levels of secretion of melatonin, using an organ culture of pineal glands. Gonadectomy 2 weeks before the animal was killed increased the amount of melatonin secreted into the medium by the pineal glands of female rats but not of male rats. The increase in in vitro melatonin secretion after ovariectomy in female rats was prevented by estrogen replacement. Ovariectomy 3 and 4 weeks before death also significantly increased the amount of melatonin secretion. Administration of GnRHa 2 weeks before decapitation significantly decreased serum estradiol concentrations and significantly increased melatonin secretion by the pineal glands of female rat. GnRHa administration 3 or 4 weeks before decapitation also significantly decreased serum estradiol concentrations, but did not increase pineal secretion of melatonin. The results indicate that ovariectomy increases melatonin secretion from organ-cultured pineal glands and that this increase is suppressed by estrogen in adult female rats. In contrast, orchiectomy in male rats does not influence in vitro secretion of melatonin. These results suggest that the GnRH-gonadotropin system may participate in the regulation of pineal melatonin secretion in adult female rats.
\end{abstract}

European Journal of Endocrinology 142 387-392

\section{Introduction}

Although mammalian melatonin production is mainly controlled by the photoperiod through a noradrenergic mechanism $(1,2)$, evidence suggests that circulating concentrations of reproductive hormones influence pineal indole metabolism (3-5). Sex steroid receptors have been identified in the rat pineal gland (6). Estradiol increases rat pineal melatonin content, and testosterone decreases it (7). However, contradictory findings have been reported on the effects of gonadectomy on melatonin synthesis or secretion in male $(8-11)$ and female $(9,11-16)$ rats. Furthermore, relatively few data on the effect of orchiectomy on melatonin production have been reported when compared with those on ovariectomy in rats.

Gonadotropin-releasing hormone (GnRH) receptors have been identified in the monkey pineal gland (3), and GnRH influences the activity of protein synthesis in rat pinealocytes (17). In addition, administration of GnRH agonist (GnRHa) to women increases nocturnal serum melatonin concentrations (18). These results suggest that GnRH may influence melatonin secretion by pineal glands.

In the present study, we evaluated the effect of gonadectomy in male and female rats, and that of GnRHa administration in female rats, on the levels of secretion of melatonin, using an organ culture of pineal glands. In addition, we examined the effect of estrogen replacement on the secretion of melatonin.

\section{Materials and methods}

\section{Animals}

Wister-Imamichi rats were maintained under controlled conditions $\left(22-23^{\circ} \mathrm{C}\right.$, humidity $\left.50-60 \%\right)$ with a photocycle of $12 \mathrm{~h}$ light: $12 \mathrm{~h}$ darkness (light on between 06.30 and $18.30 \mathrm{~h}$ ). Light intensity in the holding room was about 300 lux. The animals had Purina rat chow and water available ad libitum. Animals were killed by decapitation at 65 days of age (230-250 g body weight) at $1300 \mathrm{~h}$, without anesthesia, and then intact pineal 
glands were removed and immediately organ-cultured as described below. Trunk blood was collected and centrifuged at 1500 r.p.m. for $15 \mathrm{~min}$. The serum was then stored at $-80{ }^{\circ} \mathrm{C}$ until required for estradiol RIA.

\section{Experimental procedure}

Experiment 1 Pineal glands from 65-day-old male rats that had been either orchiectomized or sham-operated at 51 days of age were incubated.

Experiment 2 Pineal glands from 65-day-old female rats that had been ovariectomized at 51,44 and 37 days of age or sham-operated at 51 days of age were cultured. Other 65-day-old rats that had been ovariectomized at 51 days of age were given $20 \mu \mathrm{g} 17-\beta$ estradiol benzoate (Sigma, St Louis, MO, USA) subcutaneously 3 days before they were killed, and their pineal glands were also cultured.

Experiment 3 Pineal glands from 65-day-old female rats that had been administered $0.3 \mathrm{mg} / \mathrm{kg}$ body weight GnRHa (leuprorelin acetate, Leuplin, Takeda, Tokyo, Japan) subcutaneously at 51,44 and 37 days of age, or from rats that had been given saline subcutaneously at 51 days of age, were incubated.
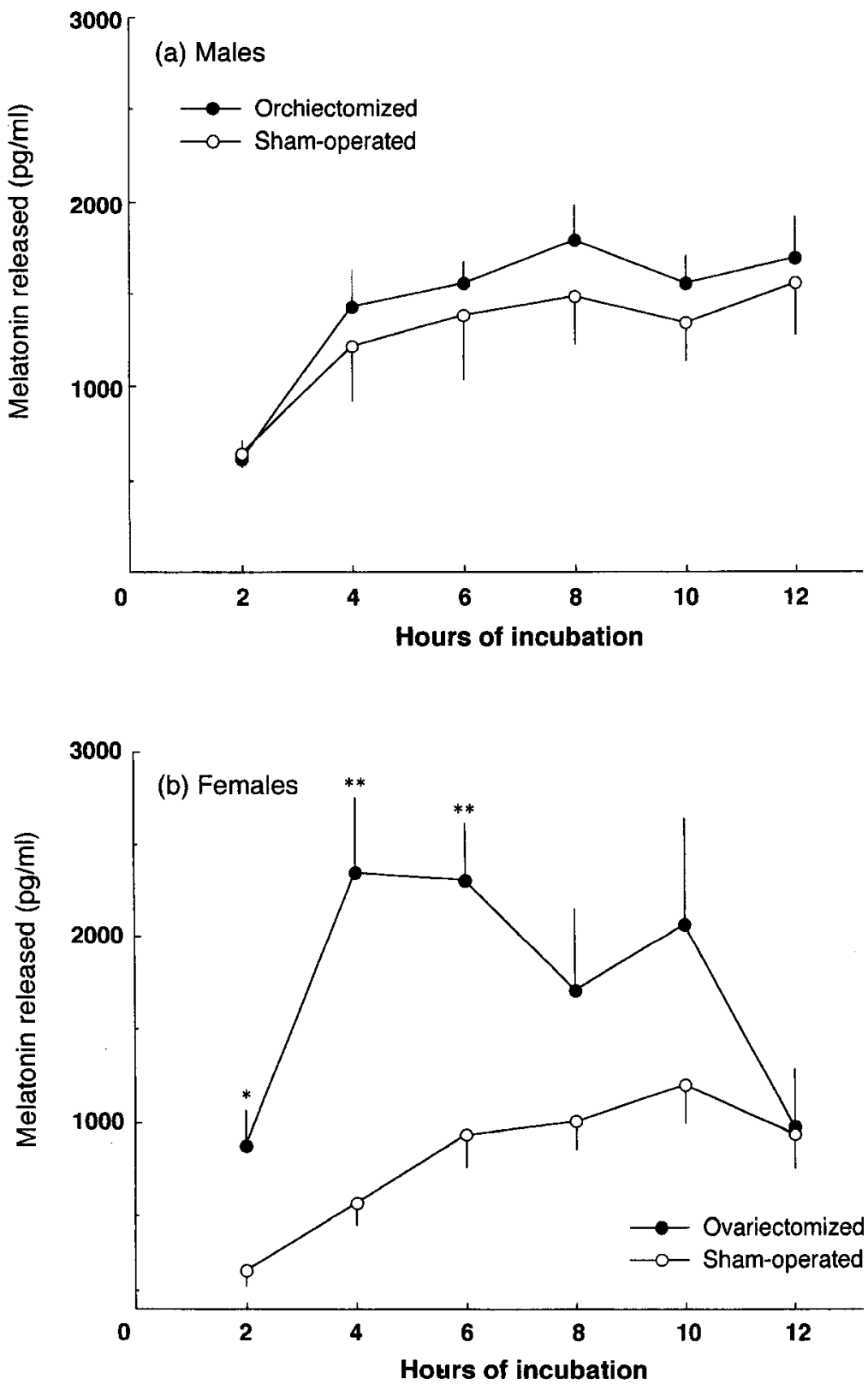

Figure 1 Effect of gonadectomy 2 weeks before decapitation on in vitro secretion of melatonin from pineal glands of 65-day-old male (a) and female (b) rats. Each point and vertical line represent the mean \pm S.E. $(n=5)$. ${ }^{*} P<0.05,{ }^{* *} P<0.01$ compared with values in sham-operated rats at the same time interval. 


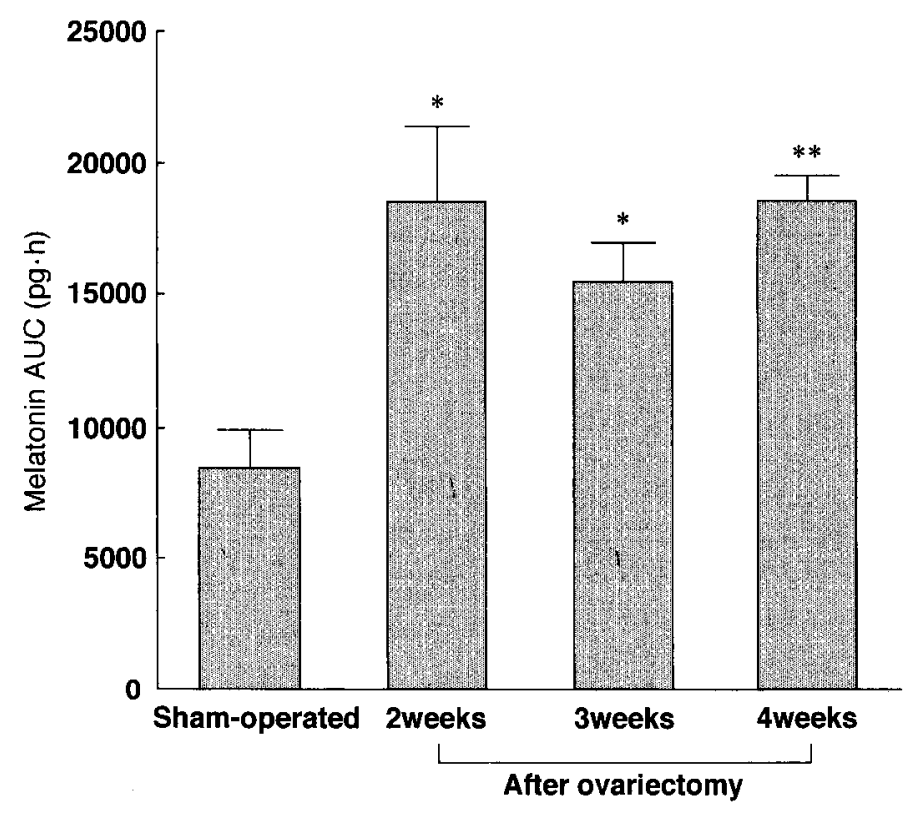

Figure 2 Effect of ovariectomy on mean in vitro secretion of melatonin AUCs of pineal glands from 65-day-old female rats. Pineal glands were obtained from female rats 2, 3 and 4 weeks after ovariectomy or 2 weeks after sham operation. Each bar and vertical line represent the mean \pm S.E. $(n=5) .{ }^{*} P<0.05,{ }^{* \star} P<0.01$ compared with values in sham-operated rats.

\section{Organ culture}

Organ cultures were prepared as described by Klein \& Rowe (19). Each pineal gland was placed on a filter (HAWP 02500; Millipore Corp, Bedford, MA, USA) that was resting on a polystyrene organ tissue culture dish (Falcon organ culture dish 3037; Becton Dickinson Labware, Franklin Lakes, NJ, USA) so designed that $1000 \mu \mathrm{l}$ culture medium, BGJb FittonJackson modification (pH 7.65, Gibco, Grand Island, NY, USA) filled the culture well and moistened the filter paper. The medium was supplemented with

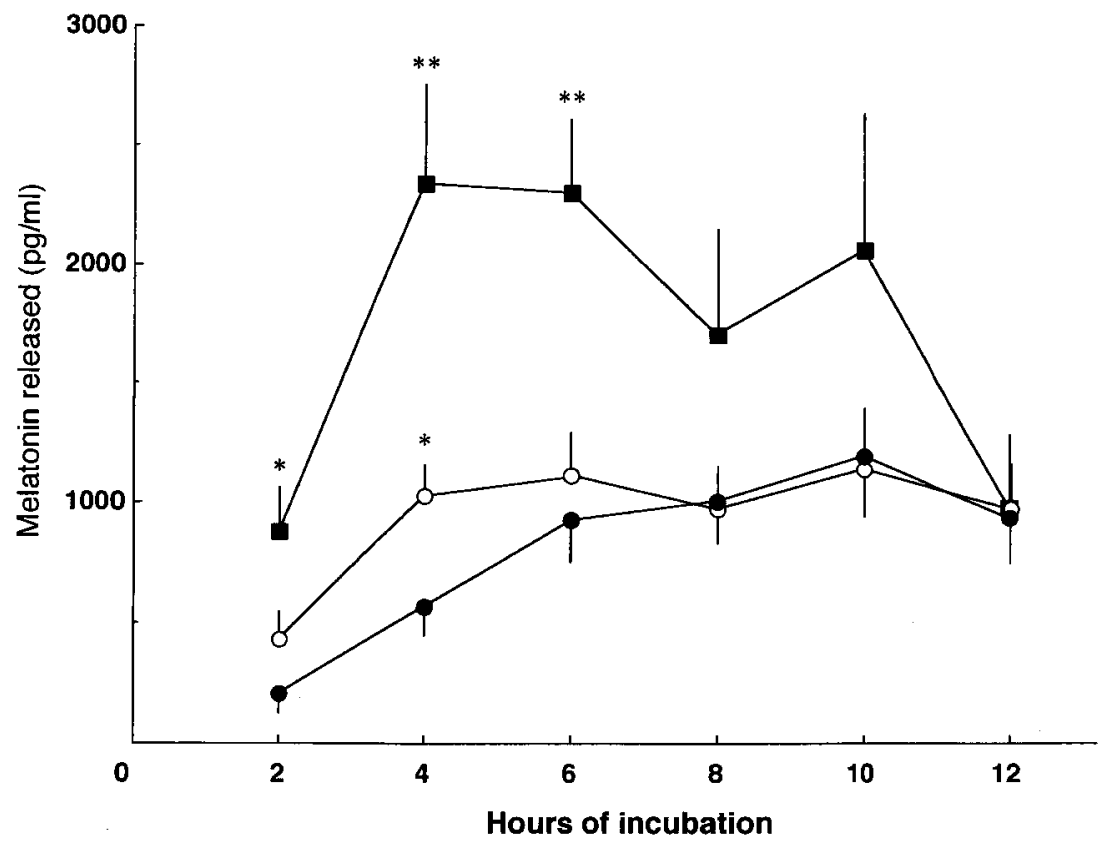

Figure 3 Effect of estradiol replacement on in vitro secretion of melatonin from pineal glands of 65 -day-old female rats. $\bullet$, sham operated at 51 days of age; $\mathbf{n}$, ovariectomized at 51 days of age; $O$, ovariectomized at 51 days of age and administered estradiol 3 days before decapitation. Each point and vertical line represent the mean \pm S.E. $(n=5) .{ }^{*} P<0.05,{ }^{* \star} P<0.01$ compared with values in sham-operated rats at the same time period. 
ascorbic acid $(0.1 \mathrm{mg} / \mathrm{ml})$, glutamine $(0.2 \mathrm{mM})$, bovine serum albumin $(1 \mathrm{mg} / \mathrm{ml})$, penicillin $(100 \mathrm{U} / \mathrm{ml})$ and streptomycin $(100 \mu \mathrm{g} / \mathrm{ml})$. The medium was changed every $2 \mathrm{~h}$ over a $12 \mathrm{~h}$ period and aspirated culture media was stored at $-80{ }^{\circ} \mathrm{C}$ until required for melatonin RIA.

\section{Melatonin and estradiol RIAs}

Melatonin concentrations in the medium were determined by RIA as described previously (20). Assay sensitivity was $15 \mathrm{pg} / \mathrm{ml}$, the intra-assay coefficients of variation were $4.5-8.3 \%$ and the interassay coefficients of variation were $7.2-16.3 \%$, depending on the concentration used. All results are based on duplicate determinations. Serum estradiol concentrations in the female rats were measured using a commercial RIA kit using COAT-A-COUNT (Diagonostic Products Corporation, Los Angeles, CA, USA).

\section{Statistics}

Data are expressed as means \pm s.E. Differences in mean values were analyzed by paired or unpaired Student's $t$-test or Mann-Whitney U-test, as appropriate. The area under the curve (AUC) was calculated from melatonin values obtained at each time point using the trapezoidal rule and the formula $1 / 2\{2(a+b)\}$ between any given two data points, where 2 stands for the distance between sampling points in hours, $a$ is the melatonin value in the medium at the first point of a given 2-h period, and $b$ is the melatonin value at the end of the 2 -h period.
Table 1 Effect of ovariectomy and estradiol replacement on serum estradiol concentrations in 65-day-old female rats at the time of decapitation. Each value represents the mean \pm S.E. $(n=5)$.

\begin{tabular}{lc}
\hline Group & Estradiol $(\mathrm{pg} / \mathrm{ml})$ \\
\hline Sham-operated & $52.3 \pm 14.4$ \\
OVX-2 & $7.6 \pm 2.6^{* *}$ \\
-3 & $6.7 \pm 3.2^{* *}$ \\
-4 & $8.3 \pm 12^{* *}$ \\
OVX-2+E & $52.6 \pm 11.1$
\end{tabular}

OVX-2, -3 and -4 , ovariectomized at 51 , 44 and 37 days of age, respectively; $\mathrm{OVX}+\mathrm{E}$, ovariectomized at 51 days of age and administered estradiol at 62 days of age. ${ }^{*} P<0.01$ compared with values in sham-operated rats.

\section{Results}

After $12 \mathrm{~h}$ of organ culture, no central necrosis was histologically evident (data not shown). No significant difference was detected between the amount of melatonin secreted by pineals from orchiectomized and sham-operated rats (Fig. 1a). However, the amounts of melatonin secreted by pineals from female rats 2 weeks after ovariectomy were greater than those from sham-operated rats between 0 and $6 \mathrm{~h}$ of culture (Fig. 1b). Melatonin secretion in AUC of pineals from rats 2,3 and 4 weeks after ovariectomy was significantly greater than that of sham-operated rats (Fig. 2).

In vitro melatonin secretion by pineal glands from female rats that had been administered estradiol after

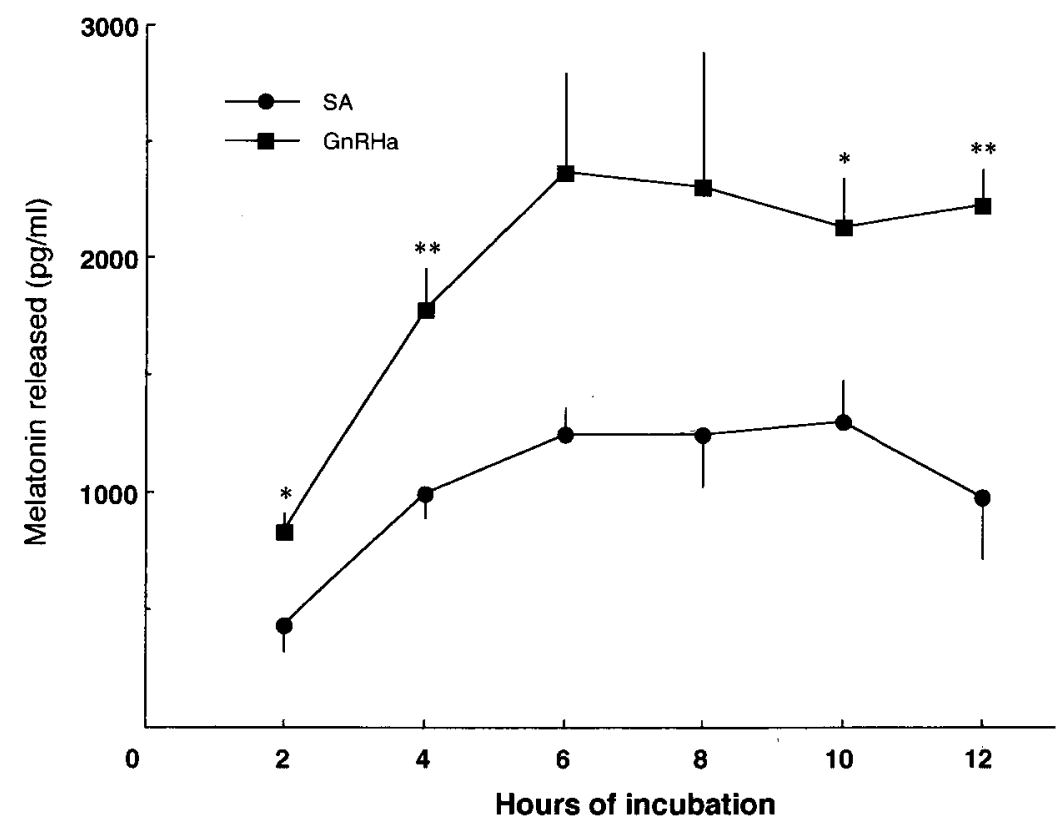

Figure 4 Effect of GnRHa administration 2 weeks before decapitation on in vitro secretion of melatonin from pineal glands of 65-day-old female rats. $\bullet, S A$, saline injection at 51 days of age; $\mathbf{n}, \mathrm{GnRHa}, \mathrm{GnRHa}$ administration at 51 days of age. Each point and vertical line represent the mean \pm S.E. $(n=5) .{ }^{*} P<0.05$, ${ }^{* *} P<0.01$ compared with values in salineadministered rats. 


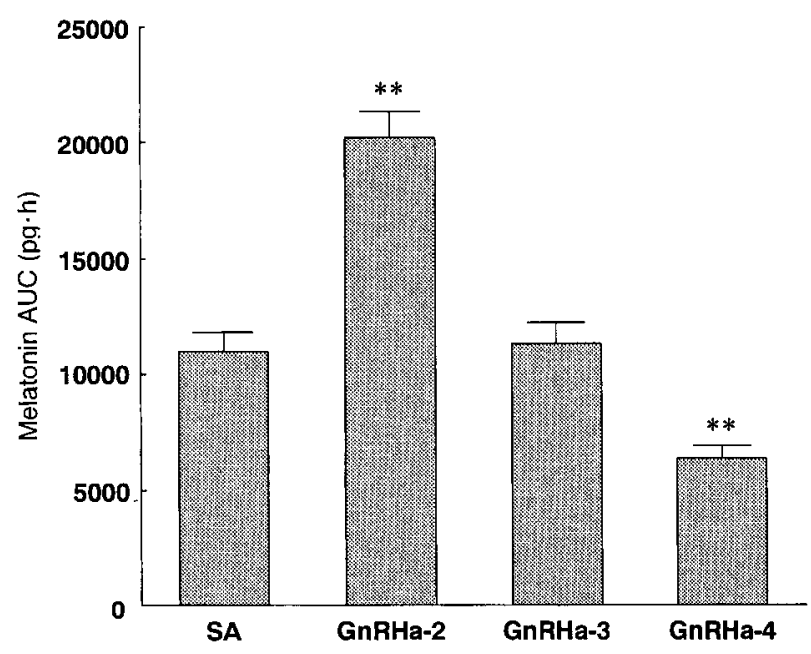

Figure 5 Effect of $\mathrm{GnRHa}$ on in vitro secretion of melatonin AUCs of 65-day-old female rats. SA, saline injection at 51 days of age; GnRHa-2, -3 and -4, GnRHa administration at 51, 44 and 37 days of age, respectively. Each bar and vertical line represent the mean \pm S.E. $(n=5) .{ }^{*} P<0.01$ compared with values in salineadministered rats.

ovariectomy was not significantly different from that by glands from sham-operated animals during the 12-h incubation period (Fig. 3).

Mean circulating concentrations of estradiol in ovariectomized rats at the time they were killed were significantly lower than those in sham-operated rats; estradiol replacement restored the serum concentrations to the preovariectomy values (Table 1).

When GnRHa was administered to female rats 2 weeks before decapitation, in vitro melatonin secretion from the pineal glands significantly increased during the 12-h incubation period (Fig. 4). Administration of GnRHa 2 weeks before decapitation significantly increased mean AUC values of in vitro secretion of melatonin from the pineal glands compared with those

Table 2 Effect of administration of $\mathrm{GnRHa}$ on serum estradiol in 65-day-old female rats at the time of decapitation. Each value represents the mean \pm S.E. $(n=5)$.

\begin{tabular}{lc}
\hline Group & Estradiol $(\mathrm{pg} / \mathrm{ml})$ \\
\hline SA & $47.3 \pm 11.3$ \\
GnRHa -2 & $2.4 \pm 0.9^{\star *}$ \\
-3 & $4.7 \pm 2.2^{\star *}$ \\
-4 & $7.3 \pm 3.2^{\star \star}$ \\
\hline
\end{tabular}

$\mathrm{SA}$, saline injection at 51 days of age; GnRHa-2, -3 and -4, GnRHa administration at 51,44 and 37 days of age, respectively. ${ }^{* *} P<0.01$ compared with values in salineadministered rats. in controls (Fig. 5). However, administration of GnRHa 3 weeks before decapitation did not affect the mean AUC values. In contrast, its administration 4 weeks before decapitation significantly reduced the mean AUC values. Mean circulating concentrations of estradiol in GnRHa-administered rats were significantly lower than those in saline-injected rats (Table 2).

\section{Discussion}

This study has shown that gonadectomy in female, but not in male, adult rats increased the in vitro secretion of melatonin from organ-cultured pineal gland (Figs 1 and 2). Estrogen replacement restored melatonin secretion to the levels observed in intact female rats (Fig. 3). Ovariectomy has been generally reported to increase the pineal or serum concentrations (or both) of melatonin in rats $(12,15,16)$. Administration of estrogen decreases isoproterenol-induced increases in pineal melatonin in ovariectomized rats $(11,21)$. The present study supports these past reports, which revealed that ovariectomy in rats increases melatonin production and that estrogen replacement reverses the melatonin concentrations to preovariectomy values. In contrast, White et al. (14) found that ovariectomy of mature rats decreased urinary excretion of 6-sulphatoxy melatonin, the metabolite of melatonin, and that administration of estradiol restored it to values found in intact animals.

Relatively few data on the effect of orchiectomy on melatonin production have been reported, compared with those on ovariectomy in rats. Most reports have suggested that orchiectomy caused a reduction in the pineal production of melatonin, as demonstrated by the changes in different parameters such as melatonin-synthesizing enzyme activities $(8,10)$. However, the present study demonstrated that orchiectomy in adult male rats did not significantly change the secretion from pineal glands removed during the day.

Administration of GnRHa 2-4 weeks before decapitation decreased the serum estradiol concentrations (Table 2). In vitro secretion of melatonin from pineal glands of female rats was increased at 2 weeks after GnRHa administration compared with that from salineadministered controls (Figs 4 and 5). Thus the hypoestrogenic state resulting from GnRHa administration caused an increase in melatonin secretion from organcultured pineals from female rats. However, in vitro secretion of melatonin from pineals was decreased at 4 weeks after GnRHa administration (Fig. 5). It has been shown that GnRH receptor is present in the monkey pineal gland (3), that GnRH influences the activity of protein synthesis in rat pinealocytes (17) and that administration of GnRHa to women increases nocturnal serum melatonin concentrations (18), suggesting that $\mathrm{GnRH}$ may participate in the modulation of melatonin production. Vacas et al. (22) reported that 
in vitro melatonin secretion from pineal glands removed from adult male rats was increased significantly by the addition of luteinizing hormone to the medium, but decreased by the addition of follicle-stimulating hormone. These reports and the present results suggest that $\mathrm{GnRH}$ and gonadotropins, in addition to gonadal steroids, may modulate the pineal levels of secretion of melatonin.

\section{Acknowledgements}

We thank Miss Yuko Abe for her technical assistance.

\section{References}

1 Binkley S \& Brammer M. Development of daily cycles in the pineal gland. In Melatonin Rhythm Generating System, pp 259-272. Ed DC Klein. Basel: Karger, 1982.

2 Abreu P, Santana C, Hernandez G, Calzadilla CH \& Alonso R. Day-night rhythm of rat pineal tyrosine hydroxylase activity as determined by high-performance liquid chromatography with amperometric detection. Journal of Neurochemistry 1987 48 665-668.

3 Pévet P. The different classes of proteic and peptidic substances present in the pineal glands. In The Pineal Gland and its Endocrine Role, pp 113-149. Eds J Axelrod, F Franschini \& GP Velo. London: Plenum Press, 1983.

4 Cardinali DP, Vacas MI, Keller Sarmiento MI, Etchegoyen GS, Pereyra EN \& Chuluyan HE. Neuroendocrine integrative mechanisms in mammalian pineal gland: effects of steroid and adenohypophysial hormones on melatonin synthesis in vitro. Journal of Steroid Biochemistry 198727 565-571.

5 Alonso-Solis R, Abreu P, Lopez-Coviella I, Hernandez G, Fajardo N, Hernandez-Diaz F et al. Gonadal steroid modulation of neuroendocrine transduction: a transynaptic view. Cellular and Molecular Neurobiology $199616357-382$.

6 Cardinali DP, Nagle CA \& Rosner JM. Control of estrogen and androgen receptors in the rat pineal gland by catecholamine transmitter. Life Sciences 197516 93-106.

7 San Martin M, Bogdan A \& Touitou Y. Day-night differences in the effects of gonadal hormones on melatonin release from perifused rat pineals. Evidence of a circadian control. Steroids $19966127-32$.

8 Nagle CA, Cardinali DP \& Rosner JM. Effects of castration and testosterone administration on pineal and retinal hydroxyindoleO-methyl transferase of male rats. Neuroendocrinology 197414 $14-23$

9 Cardinali DP, Nagle CA \& Rosner JM. Gonadal steroids as modulators of the function of the pineal gland. General and Comparative Endocrinology 197526 50-58.
10 Rudeen PK \& Reiter RJ. Depression of nocturnal pineal serotonin $\mathrm{N}$-acetyltransferase activity in castrate male rats. Journal of Neural Transmission 198048 1-8.

11 Yie S-M \& Brown GM. Effects of sex hormones on the pineal response to isoproterenol and on pineal beta-adrenergic receptors. Neuroendocrinology 199562 93-100.

12 Cardinali DP \& Vacas MI. Feedback control of pineal function by reproductive hormones: a neuroendocrine paradigm. Journal of Neural Transmission Supplementum 197813 175-201.

13 Ozaki Y, Wurtman RJ. Alonso R \& Lynch HJ. Melatonin secretion decreases during the proestrous stage of the rat estrous cycle. Proceedings of the National Academy of Sciences of the USA 197875 531-534.

14 White RM, Kennaway DJ \& Seamark RF. Estrogenic effects on urinary 6-sulphatoxymelatonin excretion in the female rat. Journal of Pineal Research 199722 124-129.

15 Okatani Y, Hayashi K \& Sagara Y. Effect of estrogen on melatonin synthesis in female peripubertal rats as related to adenylate cyclase activity. Journal of Pineal Research 199825 245-250.

16 Okatani Y, Hayashi K, Watanabe K, Morioka N \& Sagara Y. Estrogen modulates the nocturnal synthesis of melatonin in peripubertal female rats. Journal of Pineal Research 199824 224-229.

17 Haldar-Misra C \& Pévet P. The influence of luteinizing hormonereleasing hormone (LHRH) on the process of protein and/or peptide secretion characterized by the formation of granular vesicles in mammalian pinealocytes. (Comparative in vitro study.) Cell and Tissue Research 1983232 529-538.

18 Okatani Y \& Sagara Y. Amplification of nocturnal melatonin secretion in women with functional secondary amenorrhoea: relation to endogenous oestrogen concentration. Clinical Endocrinology 199441 763-770.

19 Klein DC \& Rowe J. Pineal gland in organ culture. I. Inhibition by harmine of serotonin- ${ }^{14} \mathrm{C}$ oxidation, accompanied by stimulation of melatonin- ${ }^{14} \mathrm{C}$ production. Molecular Pharmacology 19706 164-171.

20 Itoh MT, Ishizuka B, Kudo Y, Fusama S, Amemiya A \& Sumi Y. Detection of melatonin and serotonin $N$-acetyltransferase and hydroxyindole-O-methyltransferase activities in rat ovary. Molecular and Cellular Endocrinology 1997 136 7-13.

21 Moujir F, Bordón R, Santana C, Abreu P, Hernandez G \& Alonso R. Ovarian steroids block the isoproterenol-induced elevation of pineal melatonin production in the female rat. Neuroscience Letters $199011912-14$.

22 Vacas MI, Keller Sarmiento MI, Pereyra EN, Etchegoyen GS \& Cardinali DP. In vitro effects of adenohypophysial hormones on rat pineal melatonin content and release. Molecular and Cellular Endocrinology $19875023-27$.

Received 7 September 1999

Accepted 4 November 1999 